\section{Planejamento urbano em debate (coletânea de textos)}

Por Ana Helena Pompeu de Toledo e Marly Cavalcanti. São Paulo, Ed. Cortez \& Morais, 1978.

Um dos temas mais polêmicos da moderna sociologia urbana é o que trata da instauração da planificação dentro de um processo de desenvolvimento de tipo capitalista. Considerando-se, porém, o momento histórico extremamente particular que caracteriza a adoção de técnicas de planejamento no Brasil, parece-nos por demais generalizante adotar, como regra global, o que foi feito e concluído com base na experiência estrangeira.

Impõe-se, portanto, a leitura do que foi produzido por autores nacionais na área de administração e planejamento urbano.

O livro divide-se em quatro temas principais, iniciando-se pela discussão do processo de crescimento urbano no Brasil. Dentro deste tema, o artigo de Hamilton Tolosa demonstra que o II PND marca uma importante reformulação na concepção e no processo de planejamento urbano. Teoricamente, ao menos, as proposições do II PND vềm de encontro a algumas das principais críticas sobre a experiência do período anterior.

Sem dúvida, o ponto principal a ser destacado é a definição de política urbana a nível nacional, dando prioridade à implantação de áreas metropolitanas e à dinamização dos centros médios ou núcleos de apoio à ocupação terri- torial. A principal dificuldade da política urbana é seu caráter multissetorial, implicando, portanto, todas as demais políticas, sejam elas agrícolas, industriais, tecnológicas, etc.

Talvez a mais crucial questão erivolvida seja a de que, atualmente, 8,5 milhões de pessoas economicamente ativas e residentes nas nove áreas metropolitanas possuem rendimentos inferiores ao salário mínimo local. O problema se agrava ao considerarmos que, a despeito da lenta porém progressiva desconcentração do sistema urbano, as áreas metropolitanas deverão manter nas próximas décadas a sua posição de núcleo polarizador de migrantes. A comunicação de Celsius Lodder enfatiza o surgimento do sistema urbano brasileiro ern escala nacional, com hierarquia definida e funcionalmente diferente de seu predecessor.

Até o primeiro quarto deste século, num período que engloba quase 400 anos, a rede urbana, ou - sistema de cidades brasileiras, não existia senão em função de suas relações com o exterior e refletia nitidamente o caráter de exploração colonial da economia, tendo como finalidade ocupar, dominar e extrair o máximo da região em que se situava.

A urbanização - aqui entendida como um fenômeno socioeconồmico e cultural - foi profundamente modificada por seis fatores, dentre os quais se destaca a industrialização, cuja característica básica está em sua concentração em alguns pontos do espaço geográfico brasileiro. O segundo é - próprio sistema urbano, que se caracteriza por sua hierarquização, por umà população concentrada, e por não ter sido definido o tamanho médio para a sua estrutura. 0 terceiro fator é representado pelas migrações, com a predominância dos fluxos de curta distância (intraregião) sobre os de longa distância (inter-regiões). O quarto é o mercado de trabaitio urbano, cujas características estão nos niveis de subemprego e desemprego elevados.
Finalmente, o quinto fator seria - grau de concentração da distribuição de renda pessoal com elevado índice de marginalidade e pobreza urbana e o último elemento seria representado pela deficiência, em todos os sentidos, da infraestrutura dos serviços urbanos.

O segundo tema do livro contrasta duas análises radicalmente opostas para processo de planejamento e para o papel do analista de políticas do governo.

Eduardo Dutra Aydos realiza um balanço da literatura recente, abordando a convergência das modernas teorias da administração e da análise de políticas para alguns aspectos informais do planejamento, especificamente aqueles tidos como de natureza política ou inaptos a um tratamento racional. A complementaridade dos aspectos técnico e politico do processo de planejamento é sustentada numa ampla perspectiva sistêmica, reconhecendo-se um papel emergente na singularidade e dinamismo dos processos decisórios. Destaca-se, sobretudo, o modelo ótimo de decisões de Lindbloom, denominado incrementalismo disjunto, o qual propõe - em vez de simplesmente ajustar meios e fins - os mecanismos para que os fins sejam escolhidos de forma que sejam apropriados a meios disponíveis ou quase disponíveis.

Desta concepção teórica não partilha Luís Carlos Costa ao afirmar que o exame mesmo superficial do planejamento urbano no Brasil revela imediatamente a situação de crise que se manifesta tanto ao nível de prática, quantn ao da teoria; o autor procura demonstrar que, dentro do atual processo de urbanização brasileira, o modelo vigente de crescimento urbano não pode senão conduzir a impasses que resultam na precariedade cada vez maior das condições de vida urbana, no aumento dos custos de urbanização (inviabilizando a produção de equipamentos públicos), bem como na deterioração continuada das condições ecológicas e ambientais.

A grande contradição reside em se continuar falando em melhoria das condições de vida urbana e, no 
entanto, não se assumir plenamente como tarefa do Estado alterar completamente a escala e o sentido da ação executiva do poder público na cidade, passando este a funcionar como um agente imobiliário privilegiado, cujo lucro seja validado por uma aplicação no atendimento efetivo da população de baixa renda.

Celso Lamparelli faz uma análise metodológica do ṕlanejamento urbano, apontando uma dicotomia entre prática e teoria, a divisão social do trabalho, a esterilização da cooperação e da ação coletiva. Tal metodologia e sua prática podem produzir um discurso ideológico que tenderá a ocultar as intenções e interesses de grupos e seus agentes, por meio de distorções na concepção do objeto e swa problemática. Istu conduzirá, naturalmente, à seleção dos probtemas a serem, resolvidos, deixando ocultos aquetes que, sendo ou não problemas de outros niveis, nâ merecem solução, pois para determinados agentes snciais não constituem problemas, mas, provavelmente, situações que devam ser mantidas a todo custo.

O terceiro tema do livro aborda os problemas institucionais decorrentes do surgimento de grandes aglomerados urbanos no Brasil, tema este que tem sido uma constante nos debates sobre planejamento urbano e regional. Ana Helena Pompeu de Toledo coloca o conflito existente entre as esferas polítıca e técnica dentro de uma atuação racionalizada do governo, pelo confronto entre teoria e prática de um dos atuais programas de desenvolvimento regional.

\section{O Programa das Cidades} Médias, analisado pela autora, fundamenta-se na Teoria de Pólos, inicialmente elaborada por Francois Perroux; esta teoria propöe um critério para a seleção dos pólos regionais e alocação dos investimentos cuja prática no Brasil parece estar sendo descaracterizada. As razões desta defasagem encontram-se na intervenção de fatores exógenos à condução da ação racionalizada prevista pelo governo na atualidade.
Eros Grau, em seu artigo Análise, crítica e implementação da legislação metropolitana, demonstra que a realidade é uma ausência de políticas nacionais de urbanização, cujas linhas fundamentais deveriam ter sido formuladas concomitantemente com o estabelecimento das regiões metropolitanas. Extremamente árdua, portanto, é a tarefa que a lei complementar legou ao legislador estadual, ao ignorar que existem diversidades da mais variadas ordens de grandeza entre as características e os problemas das regiões metropolitanas; resta ao legislador estadual o desafio de encontrar soluções que minimizem os efeitos eventualmente desastrosos que decorrerão da sensivel elevação do nivel da despesa pública do Estado, não acompanhada de recursos financeiros que deveriam ter sido postos à disposição. dos estados pela lei complementar.

Os aspectos econômicos do meio ambiente são analisados por Aloísio B. de Araujo e Marcelo de Paiva Abreu; suas conclusões demonstram a relativa inadequação dos estudos econômicos aos reais problemas que enfrentam as sociedades contemporâneas, seja pelo irrealismo das hipóteses que tais estudos abraçam, seja pela especificidade dos problemas urbanos em economias de mercados subdesenvolvidos. O controle da poluição ambiental é apontado como - mais premente dos problemas urbanos. Isto é exemplificado por um centro considerado crítıco, a cidade do Rio de Janeiro. demonstrando-se que as considerações de ordem econômica não podem ser omitidas quando se trata de firmar diretrizes de política, pois existem efetivamente diferentes modalidades de solução para o problema ambiental, as quais gerarão necessariamente diferentes efeitos sobre a economia, particularmente sobre o comportamento dos agentes econômicos. Um fato, porém, fiça evidente: a circulação - de veículos não é a responsável pelo nivel crítico de poluição nas grandes ciidades; são sim as indústrias, e sobretudo sua aglomeração, as maiores responsáveis pela poluição atmosférica. Isto é confirmado pelo coeficiente de correlação entre partículas em suspensão (Hi-vol, $\mu \mathrm{g} / \mathrm{m}^{3}$ ) e o valor da produção industrial por $\mathrm{km}^{2}$ que alcança 0,91.

O último tema do livro refere-se aos programas habitacionais e de transporte público. Josef Barat e Mauricio Sá Nogueira Batista analisam o transporte público e os programas habitacionais, apontando as influências dos padrões de distribuição desigual da renda e dos custos de construção sobre os mecanismos de mercado que se podem revelar ineficazes no barateamento e na extensão do consumo de imóveis residenciais às camadas mais carentes da população. Isto gera concentração de recursos em áreas já congestionadas, aumentando seu adensamento e gerando, por seu turno, deseconomias externas no consumo de serviços básicos. A diferenciação espacial e o uso do solo em cidades brasileiras ocorrem pela conjugação de duas tendências: desvalorização das áreas centrais das metrópoles, no estilo norte-americano, e adensamento dos espaços intraurbanos pelo crescimento vertical da cidade, no estilo dualístico e subdesenvolvido que se aproveita mais de areas já dotadas de infraestrutura básica. Assim, o problema dos transportes depende não apenas da expansão das cidades, mas também de sua configuração e estrutura.

Em Confrontações políticas e o planejamento urbano-habitacional em debate, Marly Cavalcanti analisa os estreitos relacionamentos entre a política urbano-habitacional e os canais de participação e mobilização política. É apenas após 1964 que a política urbano-habitacional toma uma posição central nos interesses do novo governo brasileiro. No entanto, a estratégia governamental visava a fins alheios ao problema específico da habitação. Isto fica claro se pensarmos que, caso o problema habitacional fosse o foco das preocupações, outras alternativas habitacionais deveriam ter sido geradas e não o foram. A análise dos acontecimentos apoiase na dialética entre os conceitos de solidariedade e interesse, pois, à medida que se ampliam as áreas de igualdade social, são amplia- 
dos, também, os jogos de interesses dos grupos nesta sociedade. Isto, obviamente, beneficia quem detiver maiores interesses, legitimando as desigualdades sociais. A autora aplica este framework teórico aos problemas da educação e dá propriedade da moradia, demonstrando que estas políticas setoriais são pólos centrais da estratégia governamental de ampliação das igualdades, para favorecer a ampliação e o livre jogo de interesses de alguns grupos mais privilegiados na sociedade.

Concluindo, é preciso lembrar que, não obstante alguns obstáculos epistemológicos maıs sérios que se antepõem ao desenvolvimento teórico e crítico da produção do conhecimento na área urbana, a praxis do planejamento deve encontrar métodos que impeçam a continua construção da cidade dos ricos às custas e em detrimento de áreas periféricas eternamente suburbanas. Sem dúvida, este não pode ser um projeto para a convivência das classes sociais em uma cidade da segunda metade do século XX.

Ana Helena Pompeu de Toledo e Marly Cavalcantı

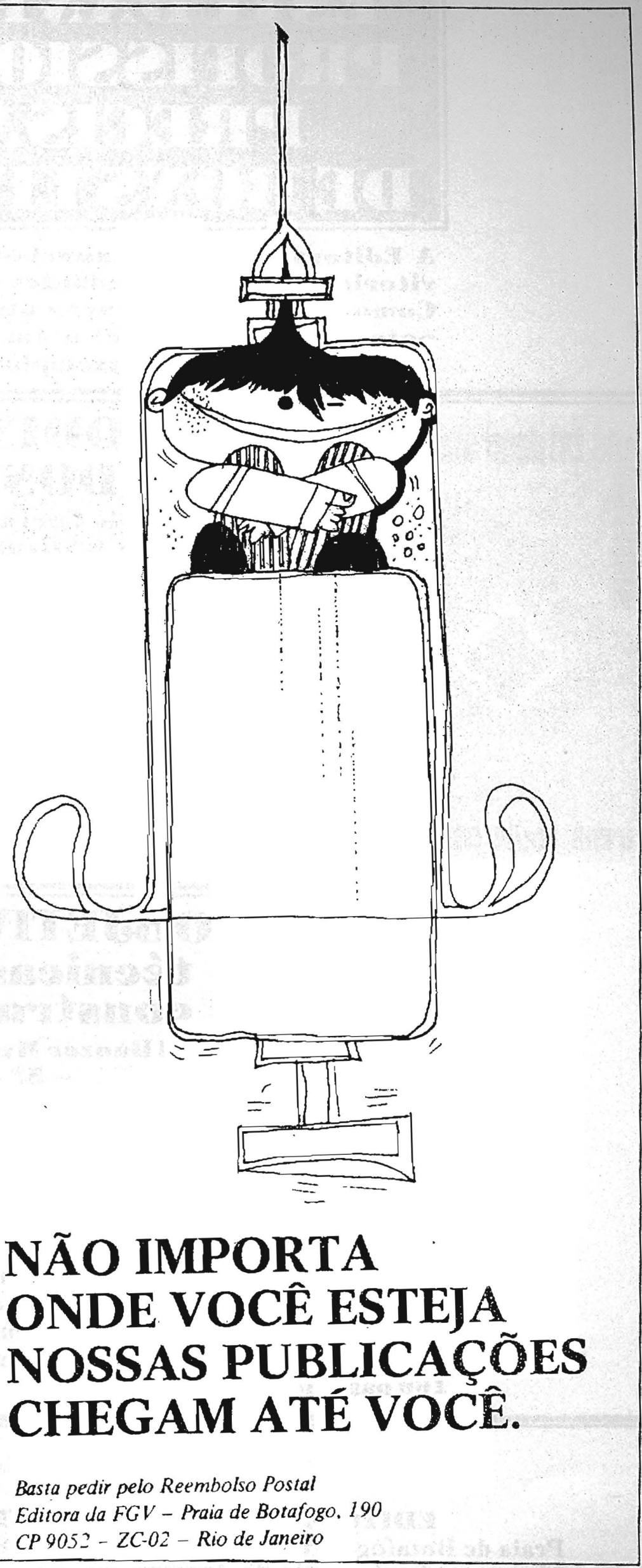

